\title{
Anatomic patterns of maxillary sinus drainage
}

\section{Andreea - Ioana Derjac-Arama', Stefania Anca Mihai', Mihai Sandulescu', Mugurel Constantin Rusu' ${ }^{1}$}

${ }^{1}$ Division of Anatomy, Faculty of Dental Medicine, "Carol Davila” University of Medicine and Pharmacy, Bucharest, Romania

${ }^{2}$ Division of Oral Implantology, Faculty of Dental Medicine, "Carol Davila” University of Medicine and Pharmacy, Bucharest, Romania

\section{ABSTRACT}

BACKGROUND. Functional endoscopic sinus surgery may be indicated when certain anatomic variations impede the normal drainage of the paranasal sinuses through the ostiomeatal complex. We aimed at studying the drainage system of the maxillary sinus which consists of the maxillary infundibulum, the main ostium of the maxillary sinus, the ethmoidal infundibulum and the hiatus semilunaris inferior.

MATERIAL AND METHODS. The study was performed retrospectively on cone beam computed tomography (CBCT) scans of 60 subjects ( $\mathrm{N}=120$ maxillary sinuses). The anatomical pattern of the maxillary sinus drainage was studied on coronal scans. RESULTS. As related to different morphological possibilities in the supero-lateral limit of the maxillary sinus drainage system, five different patterns were defined: in type I (55\%) there was no pneumatization in that situs, in type II (18\%) there was an infraorbital recess of the maxillary sinus placed above the sinus ostium, in type III (14\%) an ethmoidal recess of the maxillary sinus was expanded within the ethmoid bone, above the ethmoidal infundibulum, in type IV (3\%) there were Haller cells above the sinus ostium, while in type $\mathrm{V}(10 \%)$ there were non-infraorbital ethmoid air cells above and draining into the ethmoidal infundibulum.

CONCLUSION. It appears that CBCT is a reliable tool to make an anatomical distinction of the variable pattern of pneumatization impeding a normal drainage of the maxillary sinus, between maxillary sinus- and ethmoid-derived air-filled spaces.

KEYWORDS: nasal fossa, ethmoid air cells, Haller cell, ethmoidal infundibulum

\section{INTRODUCTION}

Functional endoscopic sinus surgery is based on the hypothesis that the ostiomeatal complex is the key area in the pathogenesis of chronic sinusitis ${ }^{1}$. Certain anatomic variants are considered as determinants of sinus disease, such as the concha bullosa, agger nasi cell, variations of the uncinate process, Haller cells, paradoxical middle turbinate or posterior nasal septal deviations ${ }^{2,3}$. However, excepting the Haller cells, these structures are not direct anatomical constituents of the drainage system of the maxillary sinus.

Failure in endoscopic sinus surgery is determined by residual air cells and adhesions in the ethmoid area, or by the maxillary or frontal sinus ostium stenosis ${ }^{4}$.
In this regard, a sound anatomical knowledge of the ostiomeatal complex and of the main drainage system of the maxillary sinus is imperative for rhinologists. We aimed at studying the possibilities of anatomic variation at that level, strictly related to the drainage pathway from the maxillary sinus to the middle nasal meatus, thus excluding more distanced variations, such as those of the middle turbinate.

\section{MATERIAL AND METHODS}

A cone beam computed tomography (CBCT) study was performed retrospectively on a randomized lot of 60 subjects which were scanned for various dental procedures. The subjects were scanned using a CBCT ma- 
chine - iCat (Imaging Sciences International), and the CT data were analysed using the iCatVision software and the application 3DVR v5.0.0.3, for the threedimensional reconstructions, the specific protocol being previously described ${ }^{5}$. The different anatomical patterns were studied on bidimensional multiplanar reconstructions (MPRs) in the axial, coronal and sagittal planes.

\section{RESULTS}

We assessed on coronal sections the anatomic structures which ensure the main drainage of the maxillary sinus: the maxillary infundibulum, the main ostium of the maxillary sinus, the ethmoidal infundibulum and the hiatus semilunaris inferior (Figure 1). These are represented schematically in Figure 2.

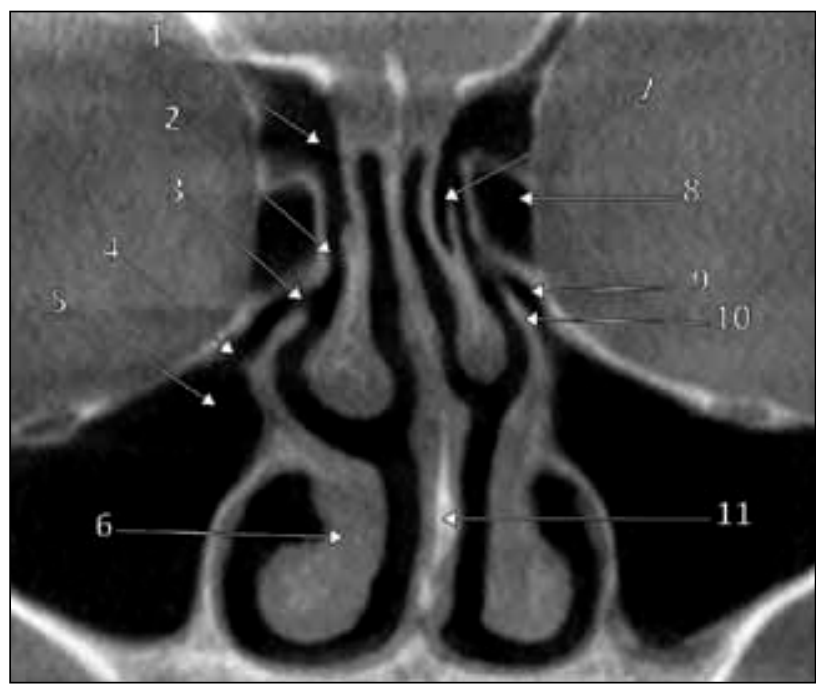

Figure 1 Coronal MPR through the drainage systems of the maxillary sinuses: 1.right frontal recess; 2 .hiatus semilunaris superior; 3.hiatus semilunaris inferior; 4.maxillary sinus ostium; 5 .maxillary infundibulum; 6 . inferior turbinate; 7 .concha bullosa media; 8.bulla ethmoidalis; 9 .ethmoidal infundibulum; 10. left uncinate process; 11 .nasal septum
We observed variable pneumatizations located in the supero-lateral wall of the drainage system of the maxillary sinus, and we classified them (Figure 3) as follows: (a) type I: absence of any pneumatization (Figure 4); (b) type II: pneumatization represented by an infraorbital recess of the maxillary sinus, placed internally to the infraorbital canal and expanding medially, eventually, as prelacrimal, or retrolacrimal recess, that means anterior or posterior, respectively, to the nasolacrimal canal (Figure 5); (c) type III: pneumatization expanding from the maxillary sinus, not in the orbit floor as in type II, but within the ethmoid (Figure 6 ), in the medial wall of the orbit (maxillo-ethmoidal or ethmoidal recess) and posterior to the nasolacrimal canal; (d) type IV: Haller cell (infraorbital ethmoid air cell) (Figure 5, Figure 7); (e) type V: non-Haller ethmoid air cell placed supero-lateral to the drainage system of the maxillary sinus and draining into the ethmoidal infundibulum (Figure 8).

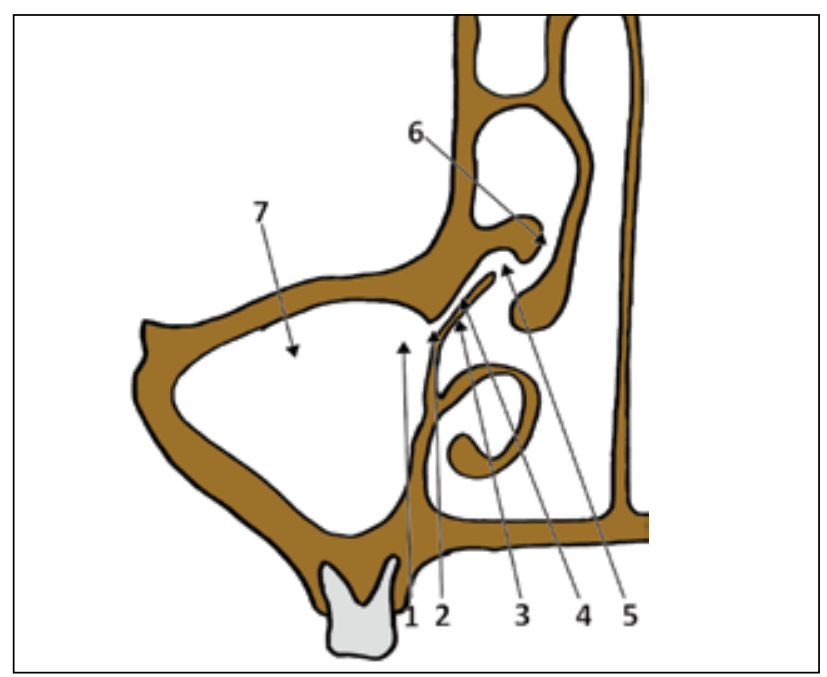

Figure 2 Schematic drawing of a coronal cut through the main drainage system of the right maxillary sinus: 1.maxillary infundibulum; 2 main ostium of maxillary sinus; 3 .uncinate process; 4.ethmoidal infundibulum; 5 .hiatus semilunaris inferior; 6 .hiatus semilunaris superior, between the maxillary bulla and the middle turbinate; 7.right maxillary sinus

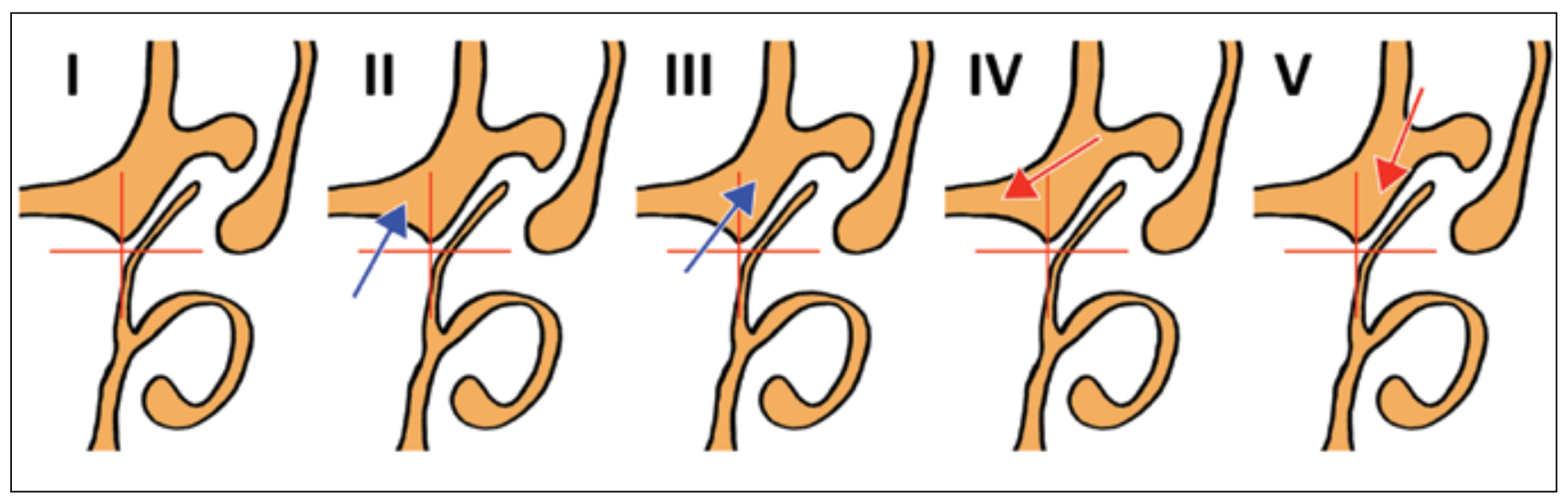

Figure 3 Anatomic variables (type I-V) in the supero-lateral limit of the drainage system of the maxillary sinus are determined either by pneumatizations expanding from the maxillary sinus (blue arrows), or by ethmoid air cells (red arrows) migrated either infero-laterally, or inferior to the ethmoid 


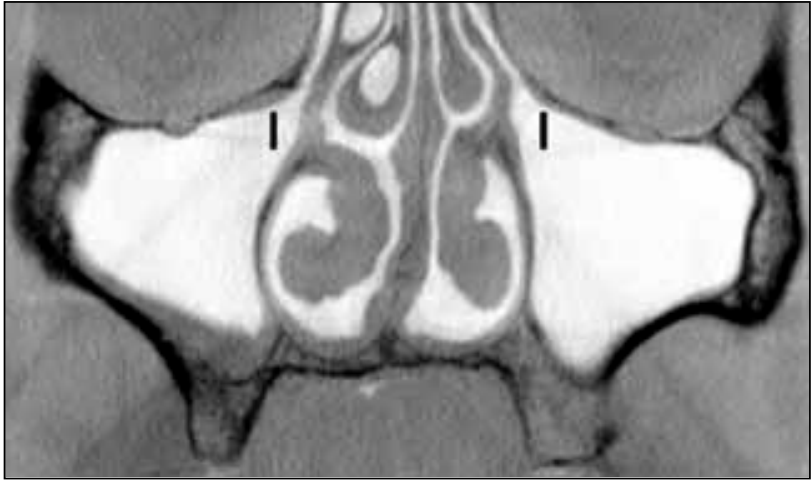

Figure 4 Coronal MPR, inverted image. Lack of pneumatization (type I) of the supero-lateral limit of the drainage system of the maxillary sinus

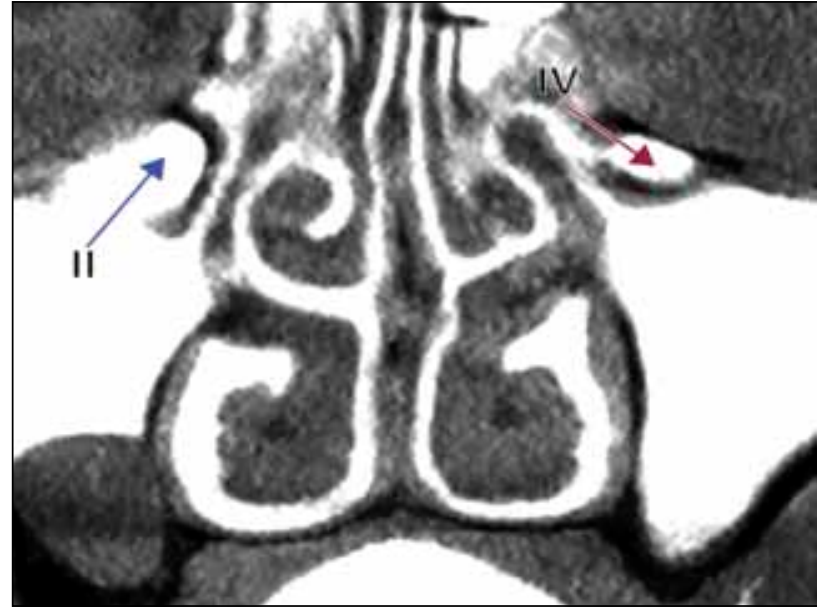

Figure 5 Coronal MPR, inverted image. Types II (right side) and IV (left side) of pneumatization of the supero-lateral limit of the drainage system of the maxillary sinus
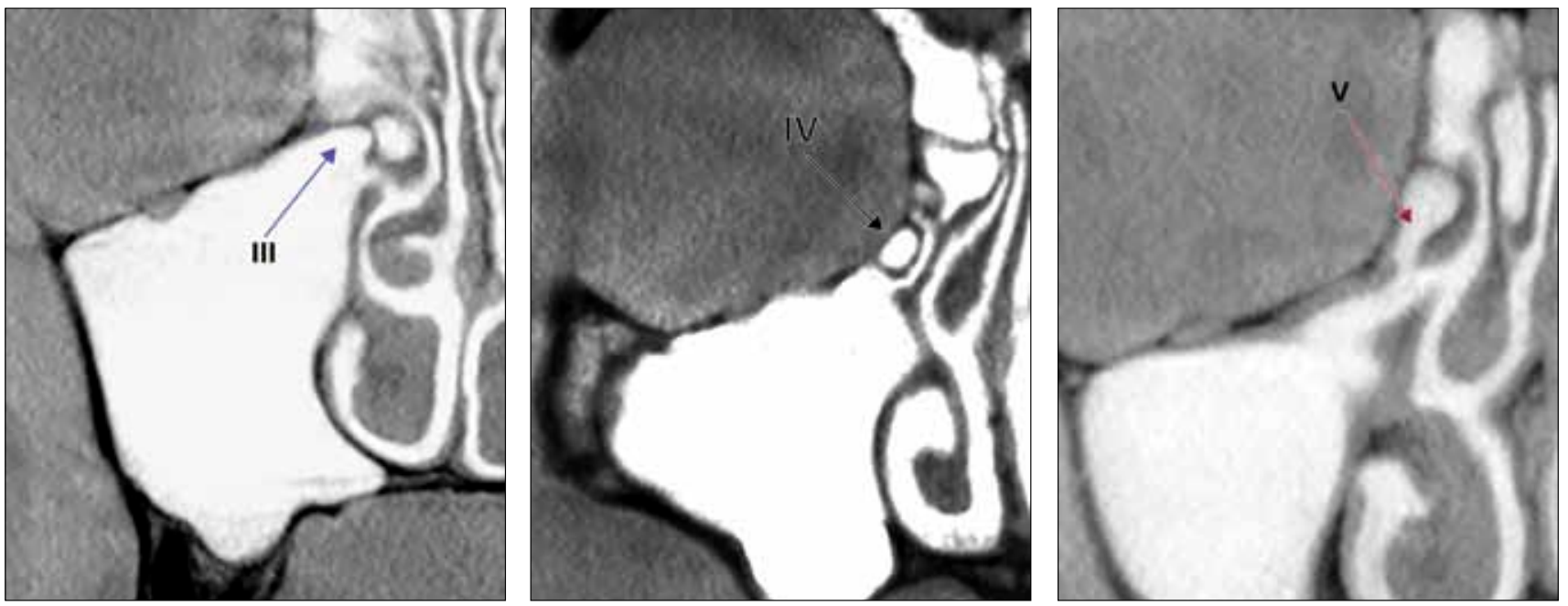

Figure 6 Coronal MPR, inverted image. Type III of pneumatization of the supero-lateral limit of the drainage system of the maxillary sinus

Figure 7 Coronal MPR, inverted image. Type IV of pneumatization of the supero-lateral limit of the drainage system of the maxillary sinus
Figure 8 Coronal MPR, inverted image. Type V of pneumatization of the supero-lateral limit of the drainage system of the maxillary sinus

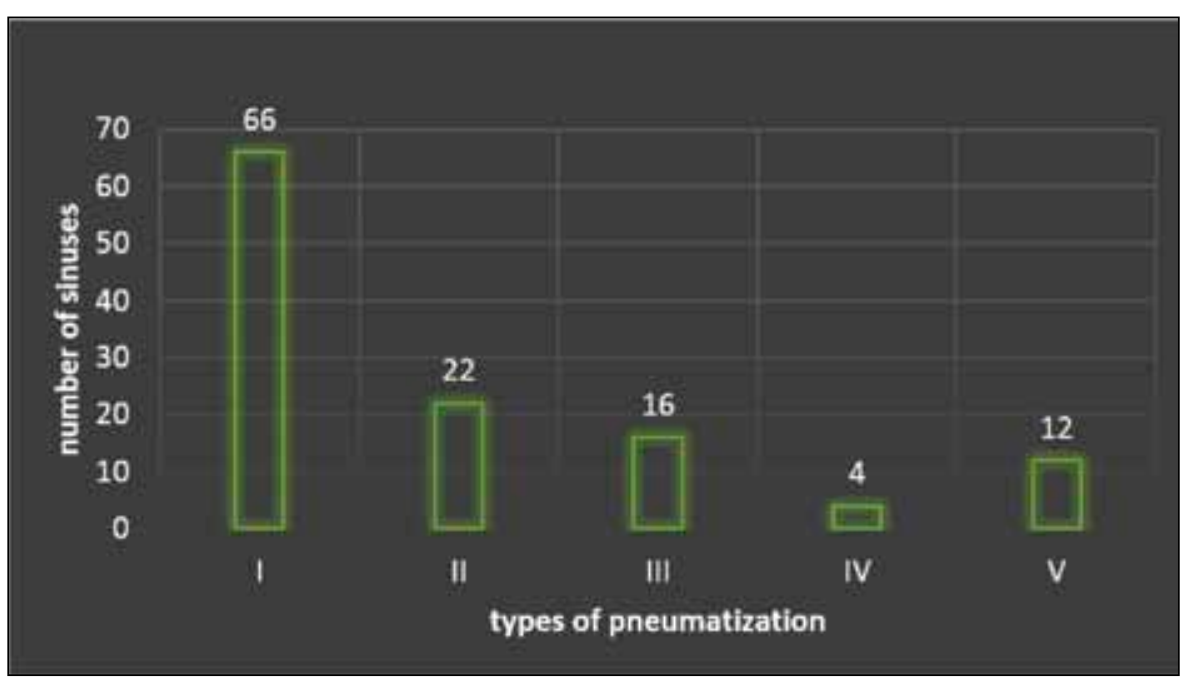

Figure 9 Prevalence of pneumatization types $(\mathrm{N}=120)$ 
From the total of 120 maxillary sinuses evaluated, $66(55 \%)$ had no pneumatization in the supero-lateral border of the drainage system of the maxillary sinus (type I). In 22 sinuses $(18 \%)$ we found a type II pattern of pneumatization. In $16(14 \%)$ we observed a type III, in $4(3 \%)$ a type IV and in $12(10 \%)$ cases we observed a type V (Figure 9). Analysis of the type's distribution with gender (Figure 10) showed that in males the types I and III were more frequent, while in females the type I was the most frequent. In 60 sinuses we found a bilateral symmetry of type I of pneumatization (Figure 11).

\section{DISCUSSIONS}

The ostium of the maxillary sinus is located on the highest part of the medial wall of the sinus, thus being poorly placed from the point of view of free drainage ${ }^{6}$.
The drainage is further restricted, as the sinus does not open directly within the middle nasal meatus, but through the ethmoidal infundibulum and the hiatus semilunaris inferior ${ }^{6}$. While the hiatus semilunaris inferior is located between the uncinate process and the ethmoidal bulla, the hiatus semilunaris superior is located between the ethmoidal bulla and the middle turbinate, communicating with the suprabullar and retrobular recesses, respectively ${ }^{7}$. Additional restrictions of the maxillary sinus drainage are determined by intimately related pneumatizations which occur in types II-V we described here.

The maxillary sinus extensions are the palatine, infraorbital, alveolar, frontal, conchal and zygomatic re$\operatorname{cesses}^{8-10}$. Haller cells are ethmoid air cells displaced into the orbit floor, which play a well stated role in the pathogeny of rhinosinusitis ${ }^{11-15}$. However, the theory of mechanical obstruction by Haller cells is disputed ${ }^{16}$. Although it is well established that Haller cells impede

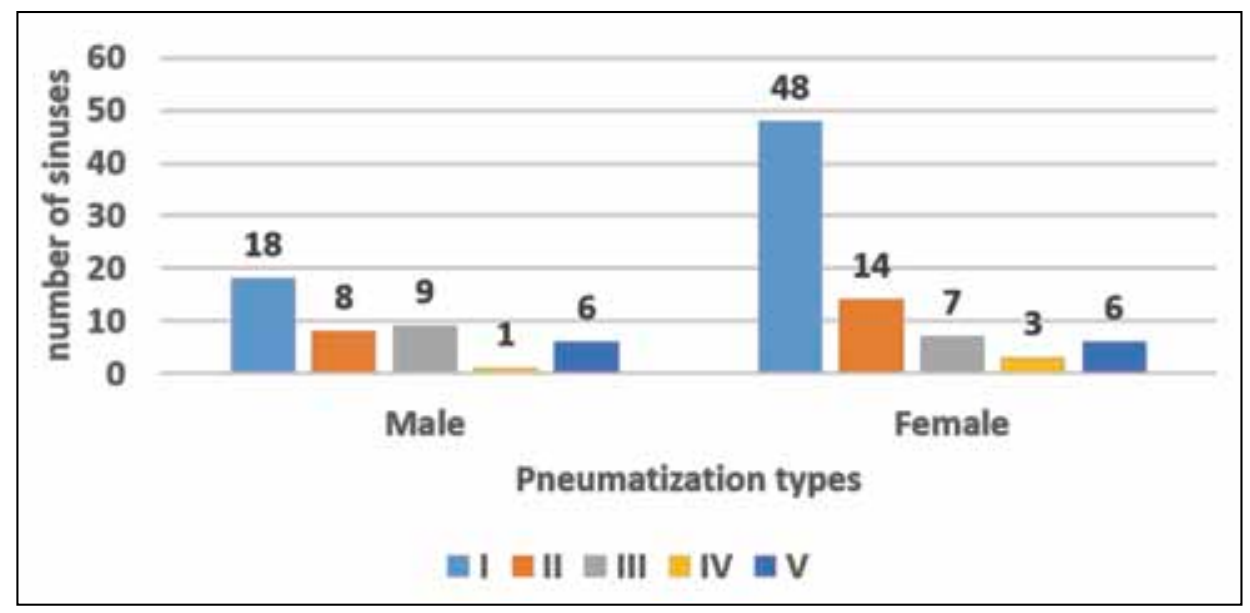

Figure 10 Prevalence of pneumatization types with gender $(\mathrm{N}=120)$

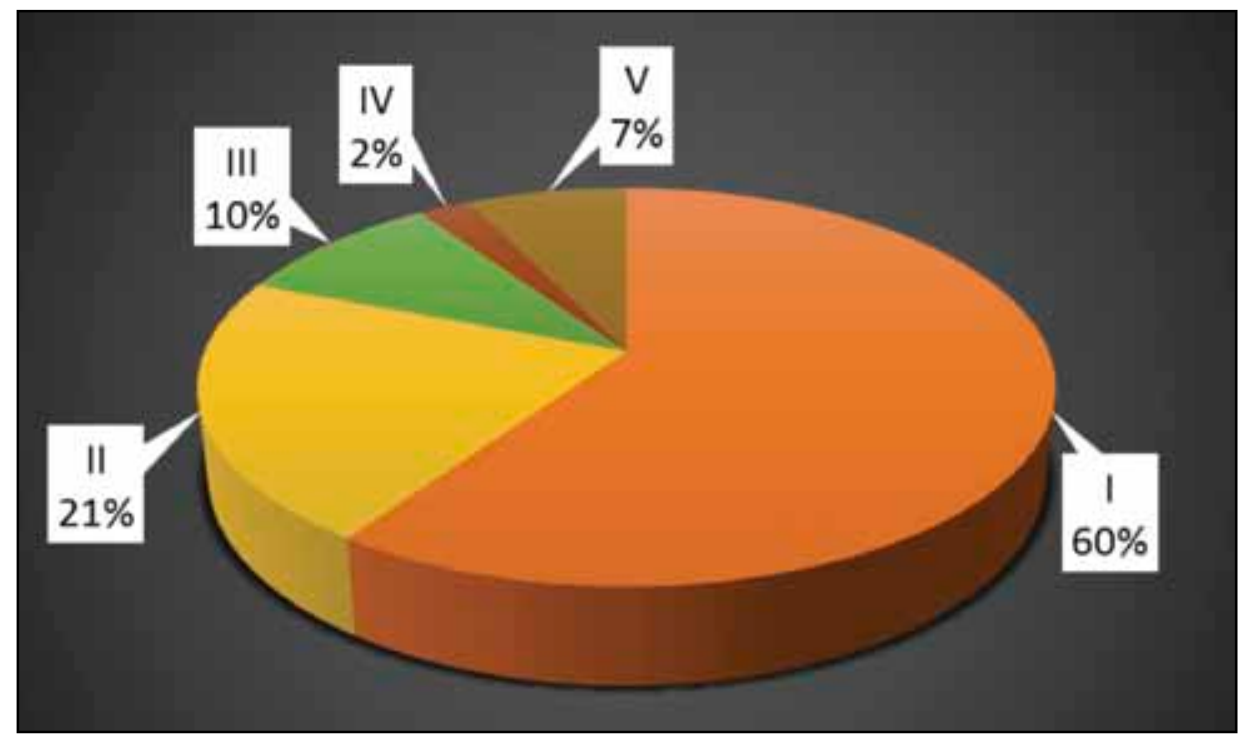

Figure 11 Distribution of cases with bilateral symmetry of pneumatization types I-V 
the maxillary sinus drainage, less attention was paid to the supero-medial extensions of the maxillary sinus we found here (types II and III). First, the infraorbital recess of the maxillary sinus is placed in the anatomical situs of a Haller cell, though it does not communicate with the middle meatus, but with the maxillary sinus. Second, the ethmoidal recess of the maxillary sinus, which is not infraorbital as it is not located in the orbit floor, nor is an ethmoid air cell, communicates with the maxillary sinus. Care should be also taken when diagnosing a Haller cell which is the most inferior infraorbital ethmoid air cell near the maxillary sinus ostium ${ }^{12}$. So, inferior but not infraorbital ethmoid air cells we found in type $\mathrm{V}$ are not Haller cells and are closely related to the ethmoidal infundibulum, and not to the maxillary sinus ostium. In CBCT, a Haller cell and an infraorbital recess of the maxillary sinus have similar appearances on coronal MPRs; distinction between these should be made on sagittal MPRs, the sinus recesses opening into the sinus, while the ethmoid air cells drain in the ethmoidal infundibulum, or directly in the middle meatus (Figure 12). The infraorbital recess of the maxillary sinus should be viewed as a false Haller cell. In this regard, studies evaluating the prevalence of Haller cells, without excluding the false ones, should be considered with caution.

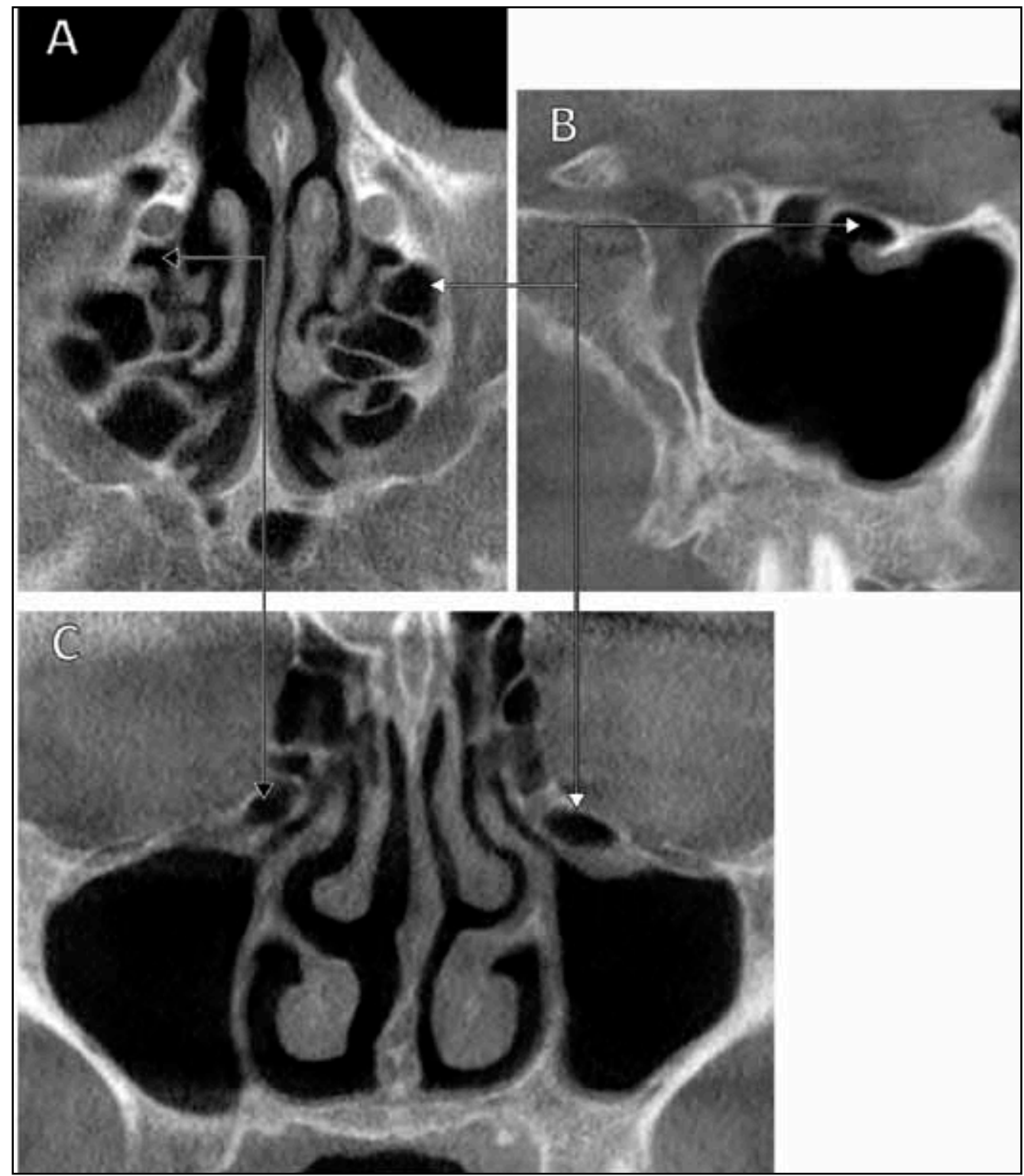

Figure 12 True (black connector) and false (white connector) Haller cells are distinguished on axial (A), sagittal (B) and coronal (C) MPRs. The false Haller cell proved being in fact an infraorbital recess of the left maxillary sinus (B). The true Haller cell is opened $(A)$ in the middle meatus. On coronal MPR $(C)$ the Haller cell and the infraorbital recess of the maxillary sinus appear similar 


\section{CONCLUSIONS}

Cone Beam Computed Tomography is a reliable tool to evaluate on a case-by-case basis the drainage system of the maxillary sinus which, in turn, is subjected to individual anatomic variation. Such anatomic variations override the definitions in the Vesalian anatomy, as previously discussed ${ }^{17-20}$.

Acknowledgements: This paper is partly supported (author \#1) by the Sectorial Operational Programme Human Resources Development (SOPHRD), financed by the European Social Fund and by the Romanian Government under the contract number POSDRU/159/1.5/S/141531.

Conflicts of interests: None.

Contribution of authors: All authors have equally contributed to this work.

\section{REFERENCES}

1. Mafee M.F. - Preoperative imaging anatomy of nasal-ethmoid complex for functional endoscopic sinus surgery. Radiol Clin North Am, 1993;31(1):1-20.

2. Wani A.A., Kanotra S., Lateef M., Ahmad R., Qazi S.M., Ahmad S. - CT scan evaluation of the anatomical variations of the ostiomeatal complex. Indian J Otolaryngol Head Neck Surg., 2009;61(3):163-168. doi: 10.1007/s12070-009-0059-8. Epub 2009 Sep 27.

3. Liu X., Zhang G., Xu G. - Anatomic variations of the ostiomeatal complex and their correlation with chronic sinusitis: CT evaluation. Zhonghua Er Bi Yan Hou Ke Za Zhi, 1999;34(3):143-146.

4. Ramadan H.H. - Surgical causes of failure in endoscopic sinus surgery. Laryngoscope, 1999;109(1):27-29.
5. Rusu M.C., Didilescu A.C., Jianu A.M., Paduraru D. - 3D CBCT anatomy of the pterygopalatine fossa. Surg Radiol Anat., 2013;35(2):143-159. doi: 10.1007/s00276-012-1009-9.

6. Prasanna L.C., Mamatha H. - The location of maxillary sinus ostium and its clinical application. Indian J Otolaryngol Head Neck Surg., 2010;62(4):335-337.

7. Stammberger H.R., Kennedy D.W., Anatomic Terminology Group Paranasal sinuses: anatomic terminology and nomenclature. Ann Otol Rhinol Laryngol Suppl.,, 1995;167:7-16.

8. Stamm A.C., Draf W. - Micro-endoscopic surgery of the paranasal sinuses and the skull base. Berlin, New York: Springer, 2000.

9. Kalavagunta S., Reddy K.T.V. - Extensive maxillary sinus pneumatization. Rhinology, 2003;41 (2):113-117.

10. Măru N., Rusu M.C., Săndulescu M. - The conchal recess of the maxillary sinus: a 100 cases CB CT study. Revista Română de Anatomie funcțională și clinică, macro- și microscopică și de Antropologie, 2013;XII:271-275.

11. Sedaghat A.R., Gray S.T., Chambers K.J., Wilke C.O., Caradonna D.S. Sinonasal anatomic variants and asthma are associated with faster development of chronic rhinosinusitis in patients with allergic rhinitis. Int Forum Allergy Rhinol.,, 2013;3(9):755-761. doi:10.1002/alr.21163.

12. Caversaccio M., Boschung U., Mudry A. - Historical review of Haller's cells. Ann Anat., 2011;193(3):185-190. doi: 10.1016/j.aanat.2011.02.006.

13. Rysz M., Bakon L. - Maxillary sinus anatomy variation and nasal cavity width: structural computed tomography imaging. Folia Morphol (Warsz), 2009;68(4):260-264.

14. Yanagisawa E., Citardi M.J. - Endoscopic view of the infraorbital ethmoid cell (Haller cell). Ear Nose Throat J., 1996;75(7):406-407.

15. Fadda G.L., Rosso S., Aversa S., Petrelli A., Ondolo C., Succo G. Multiparametric statistical correlations between paranasal sinus anatomic variations and chronic rhinosinusitis. Acta Otorhinolaryngol Ital., 2012;32(4):244-251.

16. Mathew R., Omami G., Hand A., Fellows D., Lurie A. - Cone beam CT analysis of Haller cells: prevalence and clinical significance. Dentomaxillofac Radiol., 2013;42(9):20130055. doi: 10.1259/ dmfr.20130055. 